\title{
Bee Pollen Production, Physicochemical and Bio-functional Properties, and Safety Utilization: A Review
}

\author{
Yeshitila Eshete* \\ Ethiopia Meat and Dairy Industry Development Institute, Ethiopia \\ ${ }^{\star}$ Corresponding author: Yeshitila Eshete, Ethiopia Meat and Dairy Industry Development Institute, Ethiopia
}

Received: September 17, 2021; Accepted: September 27, 2021; Published: October 11, 2021

\begin{abstract}
Pollen is a fine to coarse astonishing natural product that plays a critical role in plant reproduction. Pollen is collected when the worker bees visiting flower's blossom and their bodies touch the stamen. Pollen is collected with a pollen trap, made out of a grid, and placed on the entrance of the beehive. Beebread is bee collected pollen that stored in the honey combs and it is fermented and naturally preserved. The quality of the pollen is influenced by the harvesting techniques, technologies used, and post-harvest handling, drying and storage situations. Properly dried bee collected pollen that stored in a cool, dry and dark place keeps its sensory and microbiological quality for a storage period of two years.

Bee collected pollen is very rich in protein, fatty-acids, free sugars, carbohydrates, and it contains trace amounts of minerals, phenolic acids, flavonoids and vitamins. Pollen can be regarded as a promising therapeutic and natural food supplement. Bee collected pollen is defined as a valuable food however, due to the small quantities that are required and consumed it should be rather regarded as a supplement functional food. Its functional biological property is due to the high content of flavonoids, polyphenols and considerable radical scavenging capacity. As a functional food pollen can strengthen immunity and help the body to fight bacteria, and make the body to perform a quality tissue repair. Recently, due to the increased awareness of consumers the consumption of functional foods can improve their health and pollen began to be considered as a functional food ingredient. Pollen as bee hive product is not a widely commercialized product in Ethiopia. Having diversified natural vegetation cover that are used as a pollen source, there is a large untapped potential to produce this valuable products and then promoting and supporting pollen production and commercialization shall be the priority area of intervention in Ethiopia. The purpose of this review work is to understand and summarize the current knowledge on nutritional, bio-functional and health benefits of bee collected pollen and to set conclusion and recommendations. The review work is conducted through methods of setting the outline, reading and understanding the current articles, summarizing the relevant information's and finally set conclusion and point out recommendations.
\end{abstract}

Keywords: Flavonoids, Pollen, Beebread, Antioxident, Bioavailability, Fermentation, Pelle

\section{Introduction}

\section{Background}

Pollen is a fine to coarse powdery substance that encompasses pollen grains. Pollen grains are highly dynamic micro-scale structures with a hard coat that protects the gametophytes during the process of their movement from the stamens to the pistil of flowering plants [1]. According to pollen is an astonishing natural material that plays a critical role in plant reproduction and transfers viable cellular material between different reproductive parts of plants [2,3]. Pollen is collected when the worker bees visiting flower's blossom and their bodies touch the stamen. Bees can use the pollen for the feeding and development of the bee brood. According to pollen contains high protein that is necessary for the nourishment of honey bee broods inside the beehives [4]. Moreover, it is also the source of nutritional and mineral substances for royal jelly produced by worker bees. The average amount of pollen that a bee colony needs is estimated at 13.4 to $17.8 \mathrm{~kg}$ per year. Sufficient amount of pollen is important for colony maintenance and to increase production and productivity [5].
The pollen is compress into the pollen basket by using their hind legs. The bees moistens the pollen with secretion from its mouth which helps the pollen stick together and to the basket hairs. The bees enrich the pollen with their own substances and made a pollen pellets. The secretion from the bees contains different enzymes like. Amylase and Catalase. A pollen load contains up to 10 percent nectar, which is necessary for packing [6].

According to bee collected pollen is the main source of nutrients to the development of bee colonies $[7,8]$. Pollen is a very important factor for the development of the bee brood and supplies the necessary foods like proteins, lipids and minerals [7]. Moreover, bee pollen has gained increasing attention for its antioxidant capacity and has been used as food supplement and additives contributing on the health benefits of human [9]. On this understanding the Egyptians describe the pollen as a life-giving dust.

Pollen production allows beekeepers to diversify their sources of revenue, mitigating the effects of fluctuations in honey price and enabling beekeepers to diversify their products (Shelley et al., 2018). Pollen is collected with a pollen trap, made out of a grid, placed on the 
entrance of the hive. Based on the floral variety, pollen composed a complex chemical composition and bioactive compounds. According to bee collected pollen is the main source of protein and provides with essential amino acids that are important for brood rearing and queen feeding $[10,11]$. Bees can collect, conserve and store pollen in the hexagonal cell of the honey comb and mixing it with nectar and glandular secretions and transform into a product known as "beebread". It is a partially fermented pollen mixture that stored in the honey combs. Based on the study of bee pollen that stored in the honey comb can undergo transformation processes [12]. The transformation process can use to prolong the shelf life of the beebread and to improve the nutritional and functional properties. The biochemical transformation process is mediated by lactic acid bacteria and made a beebread [13]. The composition and nutritional value of the bee bread is different than pollen pellets. Compared to bee-pollen, bee-bread may be better tolerated by the human digestions [14].

According to the study of they characterized the bee bread as a higher nutritional value than pollen and better digestibility and richer in chemical compositions [15]. Moreover, since the components of bee bread are partially fermented it is better absorbed by the human body than pollen and is more easily assimilated [13]. On the hand the presence of high lactic-acid levels in beebread can affect storage and being a food with a short shelf life [16].

Pollen is collected when the bees pass through the openings of pollen traps on the entrance of beehives. The pollen pellets are removed and subjected to further processing and drying processes for prolonging the shelf-life. The color of pollen loads is sometimes variable and reflects the diversity of plant species that the pollen is collected [17]. According to bee collected pollen and bee bread have a high nutritional value and include bioactive compounds and regarded as functional foods [18]. The significant number of bioactive compounds, carbohydrates, enzymes, vitamins, fatty acids, essential amino acids or carotenoids depends on the botanical and geographical origin. Bee collected pollen can be regarded as a promising therapeutic and natural food supplement. Its functional biological property is due to the high content of flavonoids, polyphenols and considerable radical scavenging capacity

\section{Objectives}

\section{General Objectives}

The objectives of this review work is to understand and summarize the current knowledge, the source, production and post-harvest process, nutritional and functional benefits of bee collected pollen and to summarize the present research information's.

\section{Specific Objectives}

The Specific objective of this paper were to review

- On the current production of bee pollen.

- On physicochemical properties of bee pollen.

- On bio-functional properties and health benefits of bee pollen

- On proper utilization and handling practices of bee pollen

\section{Literature Review}

\section{Bee Pollen Production and Harvesting}

\section{Production}

Foraging bees visit different plant species to collect pollen and nectar and bring back to the beehives. According to the bees can carry the pollen by their hind legs as pollen pellets and store in the cell of honey combs [19]. During this process, the bees mix the pollen with nectar and salivary secretions and become the "bee bread," The beebread is representing a main food reserve for the development of beehive colony [20]. The quality of the pollen is influenced by the harvesting techniques, technologies used, and post-harvest handling, drying and storage situations. The humidity in pollen is an ideal culture medium for micro-organisms like bacteria and yeast. To preserve and to control the spoilage of pollen daily harvest and immediate placement in a freezer is fundamentally important to maximum the quality of pollen. Moreover, fresh bee pollen should be kept in an airtight container and should not clump together (Figures 1-6) [21].

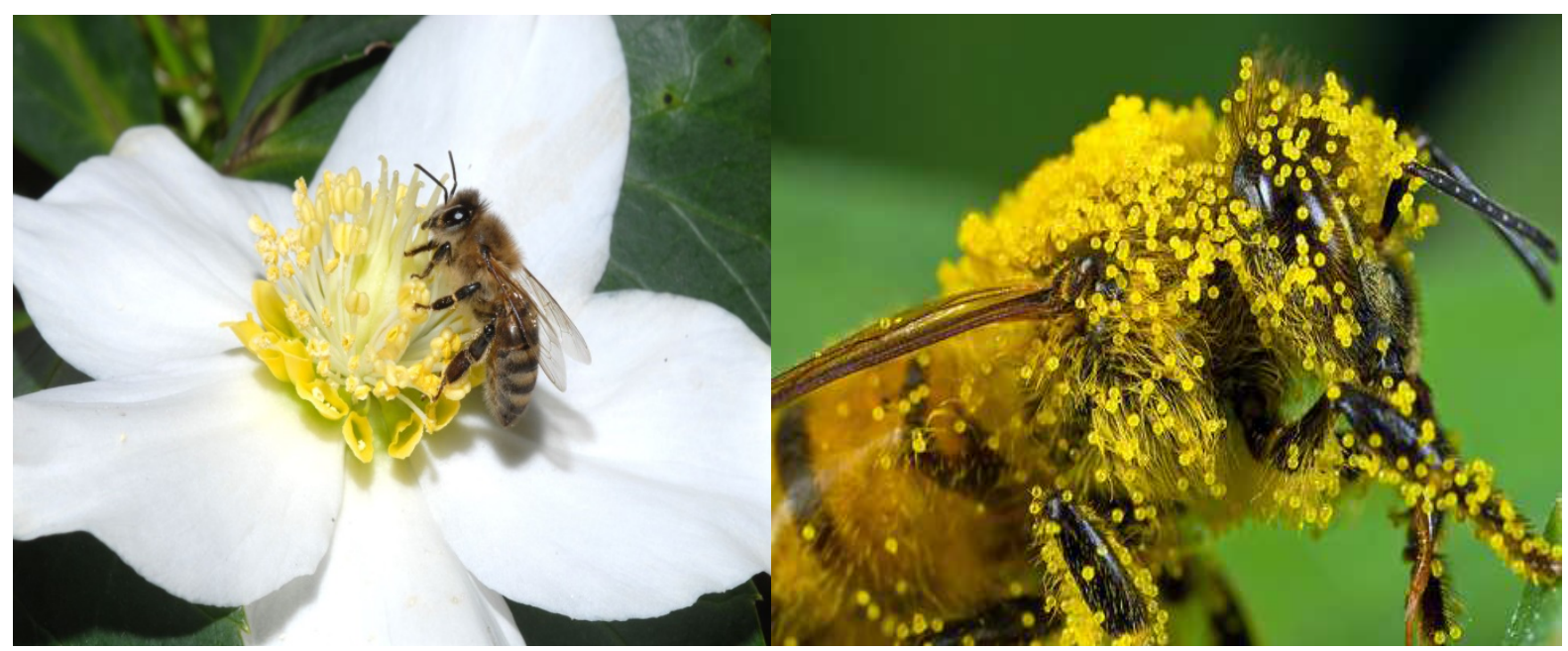

Figure 1: Bee collecting the pollen and pollen dusts on the body of the bees [62]. Source: Bogdanov (2016). 


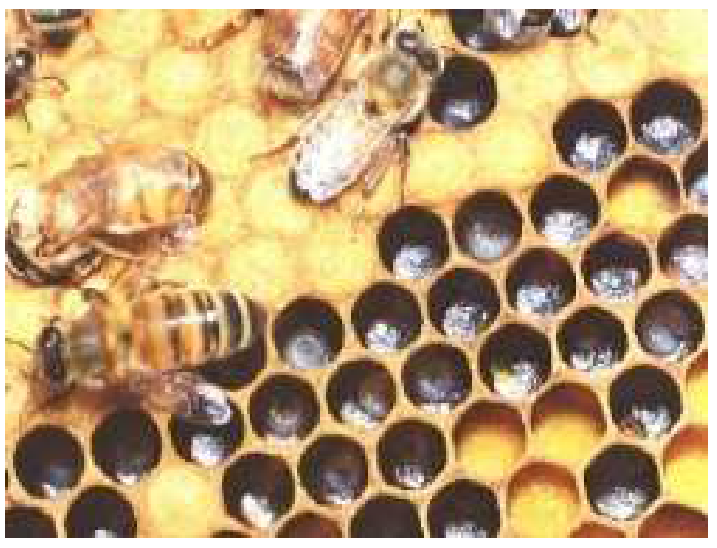

Figure 2: Bee Bread in honey comb.

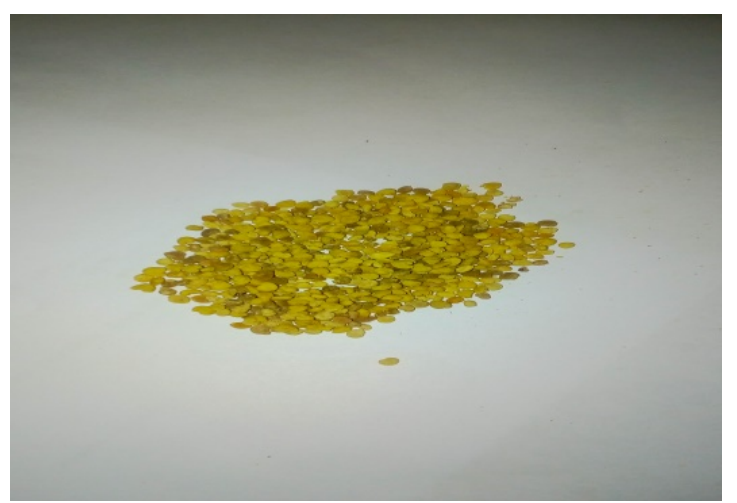

Figure 3: Pollen produced from EMDIDI demonstration site (2020).
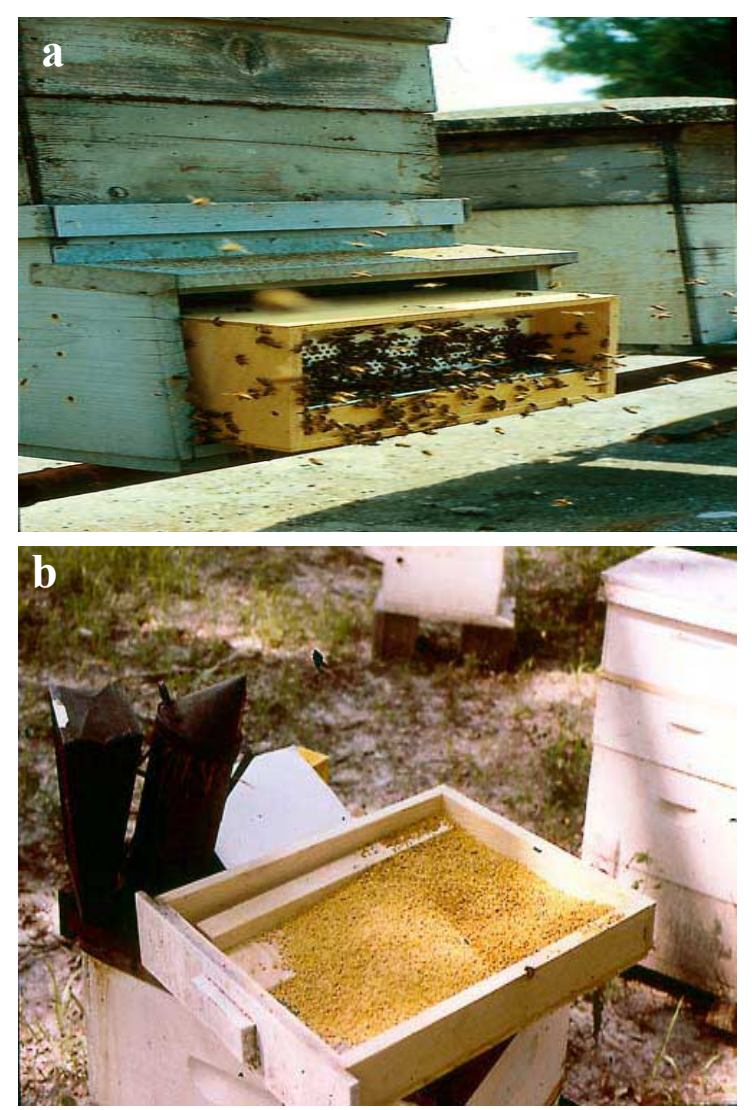

Figure 4: (a) Pollen tray fixed on the beehive (b) Harvested pollen with pollen trap.

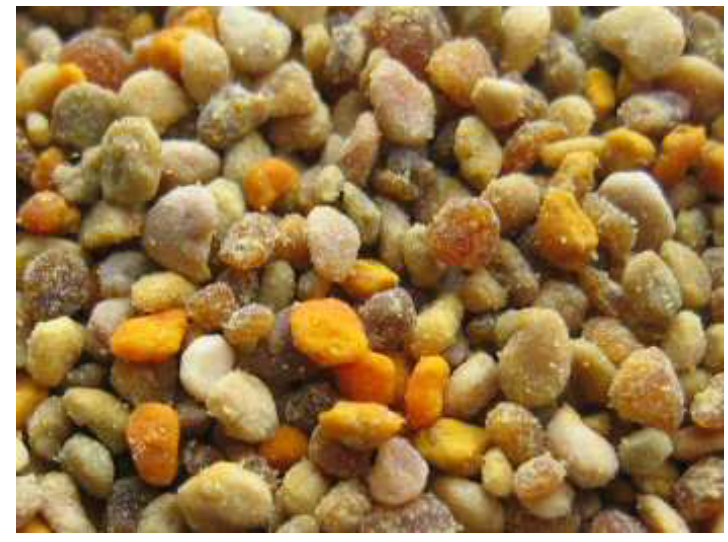

Figure 5: Dried pollen pellets. Source: Bogdanov (2016).

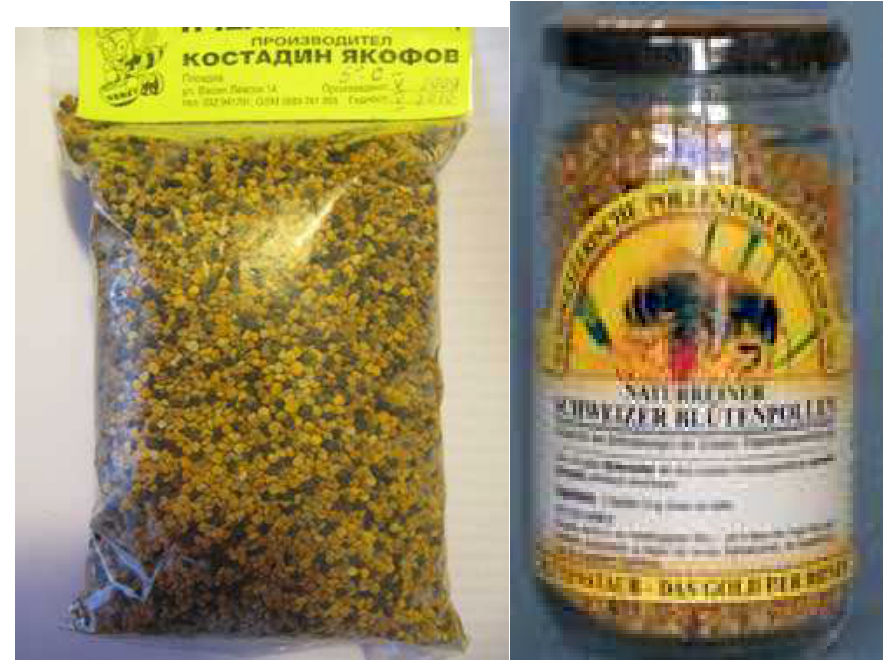

Figure 6: Commercially processed and packed pollen.

According to pollen collection has received relatively little attention when compared to honey, royal jelly, and propolis [14,21]. However, bee-collected pollen is an important source of essential amino acids, antioxidants, flavonoids minerals, vitamins, and lipids [22]. Beekeepers can fix the pollen traps in the hive entrance through which the worker bees cannot pass easily with both legs carrying pollen pellet so they are forced to drop them onto trays. The collected pollen is periodically removed from the trapping trays [23]. The pollen pellets are removed and subjected to further processing and drying processes for prolonging the shelf-life. Currently, there are only few countries like, (Spain, China, Hungary, Argentina and Brazil) where commercially produce pollen with significant contribution on national economically. Countries such as Brazil, Argentina, Switzerland, Spain and Mexico have established official quality standards and recognized pollen as a food product.

Based on the study of beebread is produced from the pollen [13]. The bees are adding honey and enzymes and transform the bee pollen to beebread. Pollen transformation in beebread occurs as a result of successive interventions of different enzymes, and some species of microorganisms, that are naturally present in pollen. According to during the fermentation process, the wall of the pollen is disrupted and makes the beebread has a better bioavailability than pollen pellets 
[12]. Comparatively with the pellets of bee pollen, beebread is better tolerated by the human organism and has a lower $\mathrm{pH}(3.8-4.3)$ [4].

Ethiopia has a huge potential to produce beehive products because of its endowment with diversity bee flora vegetation resources and climate. According to Gemechis (2014), more than 400 plant species are already identified as major bee flora plants that the bees can collect pollen and nectar. A sample of bee pollen was collected from the demonstration site of Ethiopia meat and dairy industry development institute.

According to the pollen is removed and collected from the bees by pollen traps before the bees enter in the hives [24]. Depending on, ease of cleaning, installation and harvesting there are different designs of pollen traps. Pollen should be collected daily in humid climates but less frequently in drier climates. According to avoid deterioration of the pollen and growth of bacteria, moulds and insect larvae, pollen should be air dried immediate after harvest [25]. Bees can collect about 15 to $40 \mathrm{~kg}$ of pollen per year [26]. Foraging bees carry the pollen to the hive in the form of pollen loads. Global production of the pollen is around 1500 tons per year. Depending on the pollen source plant species, the pollen grains differ in shape, color, size, and weight. The color of pollen varies, ranging from bright yellow to black.

\section{Harvesting}

Bee pollen is collected by beekeepers with the use of pollen traps, devices that fit over the entrance to a hive and contain openings just big enough for a returning forager to squeeze through [27]. In the process of squeezing through the opening in the trap, the pollen carried on the hind legs of the bee are knocked off and falls through a screen into a drawer where it is collected by the beekeeper. Pollen is collected when the bees pass through the openings of pollen traps on the entrance of beehives. The pollen stuck to the bodies of the bees falls on the trapping tray. Human intervention starts at this stage that collect, preserve, sort, purify, dry, pack and marketing for human consumption [25].

To prevent additional contamination and bacterial replication, frequent collection of pollen from pollen traps and can be need immediate air drying, processing and preservation [25].

\section{Handling and Processing}

Drying and Processing. Fresh pollen typically contains 10- 12 percent water, while the moisture content of dried pollen is around 4 percent. According to Anderson et al., drying the pollen in the sun may decrease the potency of pollen by as much as 50 percent due to oxidation of natural antioxidants in the pollen [10]. As a result, the best way to preserve pollen once it is collected is to freeze it immediately after harvest. According to some international standards of bee pollen, the maximum drying temperature is $42^{\circ} \mathrm{C}$, and water content is about 6 percent [25]. As per current Bulgarian norms, the fresh pollen, collected from apiaries, should be dried at temperatures up to $45^{\circ} \mathrm{C}$ and should have residual water content not higher than 12 percent.

The color of pollen loads is sometimes variable and reflects the diversity of plant species that. the pollen is collected [17]. The color is usually in various shades of yellow, gray-white, orange, reddish, greenish and blue. Depending of the plant species pollen grains differ in shape, color, size, and weight. The color identification of bee collected pollen pellets showed an evident variability of the botanical origin.

Preservation and Storage. Based on the data of available literature Parvanov and Dinkov (2017), the more specific requirements to the processing, storage and labeling of bee pollen as a food product are proposed with regard to food safety. Moreover, preservation of its natural physical, chemical and organoleptique characteristics can be fundamentally important aspects of pollen quality. Experience in Switzerland showed that from a microbiological and sensory point of view pollen remains stable until 1.5 years of storage at room temperature. On the other hand, according to pollen that stored in a cool, dry and dark place keeps its sensory and microbiological quality for a storage period of 2 years [28]. Besides, freezing the pollen at $-20^{\circ} \mathrm{C}$ in pure nitrogen can preserve its highest biological activities.

Beebread is a product of the hive obtained from pollen collected by bees, the bees add honey, digestive enzymes and then carried in the hive and preserved in the honey combs. According to the study of Adriana et al., and Denisow, beebread is the fermented and naturally preserved pollen that gathered by bees and mixed with its own digestive enzymes [20,28]. According to there is a significant antioxidant activity in beebread and a significant correlation between the biological activity and its botanical origin [29]. As functional food pollen is one of the main health enhancing properties, it is due to its strong antioxidant activity. However, pollen can lose a considerable amount of its antioxidant activity (about 59\%) after one year duration. This loss might be due to the decrease of phenolic compounds.

\section{Nutritional and Functional Benefits}

\section{Nutritional Importance and Quality Aspects of Pollen}

Pollen could be considered as valuable food due to its nutritional compounds like (high amounts of lipids, proteins, carbohydrates) and minerals like (Ca, $\mathrm{Mg}, \mathrm{Fe}, \mathrm{Zn}, \mathrm{Cu})$. Moreover, bee collected pollen is very rich in protein, fatty-acids, free sugars, carbohydrates, and it contains trace amounts of minerals, phenolic acids, flavonoids and a range of vitamins $[30,31]$. According to bee collected pollen and bee bread have a high nutritional value and include bioactive compounds and regarded as functional foods [18]. Moreover, pollen is rich in proteins, simple sugars, essential amino acids and omega fatty acids. According to Leila, bee pollen extract is used as beef burger fortification and also has a great inhibitory effect on lipid oxidation in beef burger [32]. It is proposed as alternative raw material to substitute a synthetic antioxidant in beef burger production. The combination of antioxidant properties with nutritive value and health-promoting effects of bee pollen suggests its potential application as food ingredient in meat products. Consequently, the need to strengthen the beekeeping productive chain, particularly in aspects related to innovation and new product development.

Current literature Adriana et al., suggests that beebread is a good source of Polyunsaturated Fatty Acids (PUFAs) that are crucial for human nutrition [28]. Beebread helps to regulate the lipid metabolism and exerts a positive effect on the immune system of patients suffering 
from chronic arthritis. Due to its rich biochemical and physicochemical composition bee pollen is preferred as a natural food supplement [33]. Bee pollen is considered an increasingly popular food supplement. Pollen consumption and marketing has recently developed. However, according to Fuenmayor et al., bee collected pollen is practically unrecognized as a food product for a long time [19]. On the other hand, chemical composition and physical parameters of bee collected pollen are primarily influenced by its floral source and geographical origin. At present there are only few countries like (Spain, China, Hungary, Argentina and Brazil) where commercially produce pollen. Moreover, countries such as Brazil, Argentina, Switzerland, Spain and Mexico have established official quality standards and recognized pollen as a food product [34].

According to there are only a few countries have established microbiological criteria for dried pollen [35]. Moreover, Switzerland, Argentina, and Brazil are the first countries that implemented official quality regulations. However, there is no specific international agreement regarding the quality of bee collected pollen (DeMelo et al., 2015). Moreover, to keep the beneficial dietary and therapeutic properties of pollen, its quality must be monitored and should be regulated [35].

Bee pollen is normally acidic, with a $\mathrm{pH}$ between 3.4 and 5.1, and composed of 15 percent proteins including essential amino acids. The nutritional and nutraceutical quality of pollen is decreased with subjected to storage conditions. However, pollen can be considered as an excellent source of polyphenols and flavonoids, considering its average content of about $1.6 \mathrm{~g} / 100 \mathrm{~g}$ and $1.4 \mathrm{gm} / 100 \mathrm{~g}$, respectively [36].

Bee pollen is defined as a valuable food however, due to the small quantities that are consumed and required, it should be rather regarded as a supplement functional food. On the other hand, even though some countries have national standard, there is no international quality and regulatory standards that defining the compositional requirements of bee collected pollen [37].

According to Bogdanov (2017), the old Egyptians describe pollen as a nurturing food. Moreover, it is known as the main exceptionally complete nourishment natural food product. Pollen provision is conveyed worldwide for dietary purposes and as diet supplement. On the other hand, the nutritional content of bee pollen may be partly released by digestive systems and only a proportion of bee pollen constituents are assimilated by humans.

The nutritional value of pollen is often evaluated by the protein and carbohydrate concentration, flavonoids and lipids content as well as the presence and quantity of essential amino acids. Bee pollen is characterized by very high protein content, but it varies greatly from 7-35 percent depending on the plant source. According to Marek, pollen can contains over 25 different micro and macro elements such as iron, calcium, phosphorus, potassium, copper, zinc, selenium, and magnesium [38]. The presence of adequate levels of macro and microelements is very important for the proper course of different metabolic processes. Moreover, mineral components are necessary for proper regulation of metabolic pathways and physiological processes [8]. Their adequate intake is essential for the maintenance of homeostasis, cell protection, functionality, and health.

The activity of pollen like vitamins and enzymes is deteriorated after two or three months of storage [13]. Scientists from the International Honey Commission (IHC), was proposed quality criteria and international standards of pollen quality. The standard is recommend the limits for the number of aerobic microorganisms $(<10 \mathrm{cfu} / \mathrm{g})$, yeast and mold $(<5.104 \mathrm{cfu} / \mathrm{g})$, Enterobacteriaceae (max $1.102 \mathrm{cfu} / \mathrm{g}$ ), E. coli (absent in $1 \mathrm{~g}$ ), Salmonellaspp (absent in $10 \mathrm{~g}$ ), and Staphylococcus aureus (absent in $1 \mathrm{~g}$ ) (Campos et al., 2008) [39].

\section{Pollen as a Functional Food}

Bee collected pollen and bee bread have a high nutritional value and rich in proteins, simple sugars, essential amino acids and omega fatty acids include bioactive compounds. Thus, compounds have a positive effect on human health and regarded as functional foods. These features strengthen immunity and help the body to fight bacteria, which will keep the body healthy and can perform a quality tissue repair of the body [40]. Furthermore, according to Margaoan et al. Bee-collected pollen and beebread are appreciated mainly for their high nutritional value [41]. Both products are rich in proteins, essential amino acids, sugars, fatty acids (including omega 3 and omega 6 fatty acids), vitamins, macro and microelements. Moreover, regarded as functional foods because they are rich in polyphenolic compounds and exhibit significant antioxidant properties [36].

Bee pollen is a valuable product greatly appreciated by the natural medicine because of its potential medical and nutritional applications [42]. It applied to antifungal, antimicrobial, antiviral, and antiinflammatory treatments. According to strong medical effect of bee pollen is originates from the richness of bioactive compounds [43]. The significant number of bioactive compounds, carbohydrates, enzymes, vitamins, fatty acids, essential amino acids or carotenoids depends on the botanical and geographical origin of the pollen. High amounts of phenolic acids and flavonoids acid stimulate antioxidant, antimicrobial, anticarcinogenic, antiviral and anti-inflammatory activities [44]. This natural product owing to its biochemical diverse could be used for immunity system enhancement, regulation of the function of digestive system, and antimicrobial, anti-aging and antianemic activities.

Antimicrobial effects of bee pollen are well known, possibly mediated by glucose oxidase activity, deriving from honeybee secretion, while plant phenolics and flavonoids could also be involved [20]. According to Marek et al., bee collected pollen remains a good source of energy having $1692 \mathrm{~kJ}$ (404.3 kcal) in $100 \mathrm{~g}$ and referred as a perfect complete foodstuff [38]. Besides, because of its unique composition, it remains termed as a super foodstuff. Recently, there has been a renewed interest in the research of the composition as well as biological properties of bee collected pollen [18].

\section{Bioactive Constituents and Health Benefits of Bee Pollen}

\section{Bioactive Constituents}

According to Afra et al., bee pollen can be regarded as a promising therapeutic and natural food supplement [45]. Its functional biological property is due to the high content of flavonoids, polyphenols 
and considerable radical scavenging capacity. However, further experimental research and clinical studies will be required to verify the effectiveness of bee pollen extracts. Various pollen products can be found on the market in the form of granules, capsules, tablets, pellets, and powders.

According to the most important bioactive substances in bee collected pollen are phenolic compounds and carotenoids [45]. The phenolic compounds are responsible for the color of the pollen grains and for the bitter taste characteristic of pollen. Carotenoids are particularly important for biological functions, such as antioxidant activity. Moreover, pollen contains more than 100 enzymes and coenzymes, 16 fatty acids, all known vitamins. Furthermore, flavonoids, carotenoids, trace elements, and antioxidants are compounds that contribute to the potential bioactivities properties of bee collected pollen [6]. The presence of more than 250 substances with high biological activity was determined in the pollen from different plant species [42].

\section{Health Benefits}

Apitherapy is becoming more and more recognized among contemporary and conventional treatment methods as it uses therapeutic effect of standardized, pharmacologically active fractions obtained from bee products [42]. The extracts of bee pollen collected from flowers of different angiosperms can be regarded as a promising therapeutic food supplement. Its functional biological property is mainly due to the high content of flavonoids and polyphenols [45]. Flavonoids and phenolic acids are the main phenolic compounds of bee-pollen and have a role in reduction of the scavenging of free radicals that harm our cells [19].

Bee collected pollen and bee bread are rich in proteins, simple sugars, essential amino acids and omega fatty acids which have a positive effect on human health. It strengthens immunity and helps the body to fight bacteria, which will keep the body healthy, and can perform a quality tissue repair [4]. According to Nemat et al., the bee collected pollen can protect the body against potentially harmful molecules called free radicals [46]. The damage the body tissue by

Table 1: Bee pollen regulatory standards of some countries.

\begin{tabular}{|l|l|c|c|c|}
\hline \multirow{2}{*}{} & \multirow{2}{*}{ Quality Parameters } & \multicolumn{3}{|c|}{ Regulatory Specifications } \\
\cline { 3 - 5 } & & Argentina & Brazil & Mexico \\
\hline 1 & $\mathrm{PH}$ & 5.00 & 5.00 & 5.00 \\
\hline 2 & Moisture gm/100gm maximum & 8.00 & 4.00 & 8.00 \\
\hline 3 & Ash gm/100gm maximum & 4.00 & 4.00 & 2.20 \\
\hline 4 & Lipid gm/100gm maximum & 6.00 & 5.00 & 6.50 \\
\hline 5 & Proteins gm/100 minimum & 15.00 & 8.00 & 12.00 \\
\hline
\end{tabular}

Source: Enero (2014) free radicals is linked to chronic diseases such as cancer and type two diabetes.

The studies of the past few years suggest that the biologically active substances found in bee pollen can act as strong antimicrobial, antioxidant and anticarcinogenic properties [43]. On the other hand, bee pollen can demonstrate a wide range of healing effects and increase the level of (Adenine Tri phosphate) ATP, and consequently neutralize an effect of many toxic agents, besides increase immunity and improve the energy balance of the tissues [38]. Moreover, antioxidants in bee pollen may protect lipids from oxidizing. The oxidization of lipids can restrict blood vessels and raising heart disease risk [47]. On the other hand, bee collected pollen may boost the immune system and help to avoid illnesses and unwanted reactions in the body and kill potentially harmful bacteria such as E. coli, Salmonella, Pseudomonas aeruginosa [48]. Strong medical benefits of this bee product originate from the richness of bioactive compounds.

According to the diversity of active natural metabolites, especially vitamins, carotenoids, and polyphenols, in pollen has valued significant biological activity [49]. Moreover, pollen can be expressed as the antioxidant, antibacterial, and anti-carcinogenic activity. According to the beneficial effect of bee pollen in the human diet, is considered as a health-promoting food [50]. Pollen has a great role in the protection of vital cell components from oxidative damage of free radicals. Pollen can neutralize the free radicals and prevent incidence of various diseases such as cancer and cardiovascular and neurodegenerative diseases [49]. Due to the high nutritional value and pronounced health-promoting properties, and the potential use as a supplement to the human diet, bee-pollen represents a valuable natural product. Pollen remains perceived as a society drug in China and Germany as a result of having a few important phytochemicals, flavonoids and carotenoids [51].

\section{Physicochemical Characteristics and Chemical Compositions}

\section{Physicochemical Characteristics}

Physicochemical characteristics of bee pollen depend on its botanical origin and the nutritional composition has some variations among different countries (Tables 1 and 2). There are plenty of studies that focus on the characterization of physical-chemical properties of bee-pollen. According to Leila, bee pollen is studied as potential treatments that suit to enhanced nutritional and bioactive value for humans. The physicochemical properties of bee-collected pollen can be affected both by processing techniques Ranieri et al., and storage conditions [52]. Freshly collected pollen contains from $15 \%$ to $30 \%$ of water. Consequently, it needs to be promptly processed to boost its physicochemical stability and avoiding microbial development [53].

Table 2: Pollen and bee bread in reference to human nutritional requirements.

\begin{tabular}{|l|l|l|l|l|l|}
\hline No & Component & Bee Pollen & Bee Bread & RDI for 15 g & References \\
\hline 1 & Proteins & $7-40 \%$ & $14-37 \%$ & $5-22 \%$ & Kaškoniené 2015; Fuenmayor et al., 2014; Hoffman et al., 2013; Zuluaga et al., 2015 \\
\hline 2 & Carbohydrates & $24-60 \%$ & $24-34 \%$ & $1-4.6 \%$ & Barene et al., 2015 \\
\hline 3 & Lactic acid & $0.56 \%$ & $3.2 \%$ & - & Barene et al., 2015 \\
\hline 4 & Lipids & $1-18 \%$ & $6-13 \%$ & $0.1-4 \%$ & Campos et al., 2016 \\
\hline 5 & Flavonoids & $0.2-2.5 \%$ & $0.03 \%$ & - & Komosińska et al., 2015 \\
\hline
\end{tabular}


According to Urcan et al., the chemical composition of bee collected pollen depends strongly on botanical and geographic origin, climate, soil type and season [54]. The bees are very selective when gathering pollen and that the bulk of the collected pollen comes from few plant species. On the other hand, the identification of botanical origin of both pollen and beebread is of paramount importance since their biological, nutritional, antioxidant and antibacterial properties are directly related to their composition [55].

\section{Chemical Composition}

According to Sattler et al., the chemical composition of bee collected pollen is fundamentally influenced by the botanical diversity from which it was collected [7]. On the other hand, the botanical contribution, storage time, nutritional status of the plant and environmental conditions in the phase of pollen collection are also influence the composition. Pollen is rich in biologically active substances and composed of about 200 substances [42]. The basic chemical substances are proteins, amino acids, carbohydrates, lipids and fatty acids, phenolic compounds, enzymes, and coenzymes as well as vitamins and bio-elements.

Small differences among composition of bee pollen could results in gathering area or season in floral species, environmental conditions including soil type, however, the major differences are mainly attributed to botanical origin [56]. According to Silva et al., the chemical composition of bee pollen depends strongly on the plant source and geographic origin [57]. Based on the study of Komosinska et al., bee pollen is normally acidic, with a $\mathrm{pH}$ between 3.4 and 5.1, and composed of $20 \%$ proteins (including essential amino acids) such as methionine, lysine, threonine, histidine, leucine, isoleucine, valine, phenylalanine, and tryptophan [42]. Moreover, bee collected pollen contains $55 \%$ total carbohydrates with $25 \%$ of reducing sugars (primarily fructose and glucose), $5 \%$ lipids, $1.6 \%$ phenolic compounds, $0.7 \%$ vitamins, and $1.6 \%$ bio chemical-elements [19].
According to proline and glutamic acid content of bee pollen is associated with bee pollen quality [58]. Moreover, concentration glutamic acid greater than $20 \mathrm{mg} / \mathrm{g}$ indicates the freshness, whereas lower proline value indicates aging and technological process. Amylase, phosphatase and glucose-oxidase are the functional enzymes that found in beebread [13]. Additionally, beebread contains largest quantity of amino acids like glutamic acid, aspartic acid and proline.

The study conducted by Adriana et al., conclude that beebread is categorize as a valuable special foods, that contains proteins, essential amino acids, fatty acids, carbohydrates, minerals and bioactive compounds [28]. The calcium content of Ethiopian Zea mays pollen investigated by Admassu was higher than potassium content a different situation comparative with previous scientific basis [59]. The pollen composition varies greatly according to its botanical origin. Table 3 presents average bee-pollen composition as well as the data of Brazilian, Hungary, Poland, Slovenia, India, Romania, Spain, China and Bulgaria. And Table 1 represents the quality parameters and regulatory specifications of pollen from Argentina, Brazil and Mexico.

The study on Rodica et al., is discover that the bee collected pollen and bee bread have a high nutritional value including bioactive compounds, which have a positive effect on human health [4]. These products are rich in proteins, simple sugars, essential amino acids and omega fatty acids. Beebread, that a product of bee collected pollen has become lately a product of high commercial value and a fair evaluation of chemical composition is needed to guarantee the quality.

\section{Utilization and Handling Practices of Bee Pollen}

The crude nutrients measurement in bee collected pollen and bee bread cannot accurately determine their nutritional and functional value. Consequently, the nutrients are encapsulated inside the hard to crack pollen grains that affect the digestibility and bioavailability the

Table 3: Physicochemical composition of commercial bee collected pollen from different countries.

\begin{tabular}{|c|c|c|c|c|c|c|c|c|c|}
\hline \multirow{2}{*}{ No } & \multirow{2}{*}{ Parameters } & \multicolumn{8}{|c|}{ Countries } \\
\hline & & Hungary & Poland & Slovenia & India & Romania & Spain & China & Bulgaria \\
\hline 1 & $\mathrm{pH}$ & 4.40 & 4.50 & 5.40 & 4.30 & 4.90 & 4.40 & 5.00 & 4.40 \\
\hline 2 & Free acidity (meq-kg) & 243.00 & 332.00 & 207.00 & 383.00 & 237.00 & 241.00 & 351.00 & 310.00 \\
\hline 3 & Moisture (gm/100 gm) & 4.90 & 4.00 & 5.90 & 9.10 & 5.10 & 5.20 & 2.00 & 4.60 \\
\hline 4 & Ash (g/100 g) & 1.70 & 2.60 & 2.40 & 3.30 & 2.30 & 1.60 & 4.30 & 1.80 \\
\hline 5 & Lipids (gm/100 g)m & 4.90 & 5.70 & 5.90 & 8.00 & 4.90 & 5.00 & 5.20 & 5.60 \\
\hline 6 & Protein $(\mathrm{gm} / 100 \mathrm{gm})$ & 16.30 & 25.60 & 21.40 & 26.10 & 22.30 & 20.80 & 17.60 & 19.20 \\
\hline 7 & Sodium (mg/kg) & 219.00 & 236.00 & 240.00 & 113.00 & 84.00 & 379.00 & 125.00 & 199.00 \\
\hline 8 & Potassium (mg/kg) & 3607.00 & 5797.00 & 5244.00 & 4794.00 & 4869.00 & 3622.00 & 9542.00 & 4608.00 \\
\hline 9 & Calcium (mg/kg) & 1461.00 & 1654.00 & 1462.00 & 2376.00 & 1657.00 & 589.00 & 1620.00 & 665.00 \\
\hline 10 & Iron $(\mathrm{mg} / \mathrm{kg})$ & 40.90 & 56.20 & 42.10 & 197.00 & 89.40 & 57.70 & 63.30 & 47.40 \\
\hline 11 & Magnesium (mg/kg) & 635.00 & 1194.00 & 1135.00 & 1430.00 & 865.00 & 484.00 & 2636.00 & 577.00 \\
\hline 12 & Zinc (mg/kg) & 34.30 & 53.20 & 44.30 & 31.30 & 48.70 & 44.30 & 31.40 & 51.90 \\
\hline 13 & Insoluble Dietary fiber (gm/100 gm) & 9.60 & 5.70 & 0.00 & 12.80 & 8.00 & 8.60 & 0.00 & 5.90 \\
\hline 14 & Soluble Dietary fiber (gm/100 gm) & 0.80 & 2.30 & 0.00 & 1.70 & 0.90 & 3.20 & 0.00 & 2.00 \\
\hline 15 & Total dietary fiber (gm/100 gm) & 10.50 & 8.10 & 0.00 & 14.60 & 9.00 & 11.90 & 0.00 & 7.90 \\
\hline
\end{tabular}

Source; Fuenmayor (2014). 
nutrients in the pollen. Moreover, according to Zuluaga et al., pollen is partially digested in human body on average about 60 percent of proteins in the pollen is digested, while the digestibility of protein in beebread is about 94.7 percent [26]. The digestibility and bioavailability of pollen is directly related to the morphological characteristics of the outer wall of the pollen [34].

The outer layer of the pollen is partly fractured during the natural fermentation and transformation process in beebread. Thus, makes beebread a better bioavailability than pollen and therefore, the functionally and energetically rich content of pollen can be assimilated and used easier by the human body (Mutsaers et al., 2005). The quality of bee pollen, in terms of nutrition, depends mainly on its digestibility and bioavailability.

According to Fan et al., pollen grain outer walls consist of two layers: the outermost (exine) and the inner surface (intine), thus layers are affect the bioavailability of nutrients in the pollen and hence, before consumption further softening process and treatment is important [3]. In order to increase the digestibility, pollen grains are crushed or dissolved in warm water and the pollen grains crack after $2-3 \mathrm{~h}$, and leads to the release of nutrients. In addition, pollen may be mixed with many other food products, for example, with honey, yogurt, and jams [40]. Pollen shall need to chew thoroughly because in raw form of pollen only $10 \%-15 \%$ the nutrients are used however, the mechanical grinding process, improve the bioavailability of this product's by $60-80 \%[42]$.

Based on the study of Aleksandar et al., pollen is recognized as an excellent dietary supplement for human nutrition [49]. Moreover, pollen as food supplement sources can be found in different forms on the market (granules, capsules, tablets, pellets, and powders). However, the digestibility of pollen's nutrients is strongly affected by the presence of a pollen shell. The shells of the pollen grain can decrease the bioavailability of nutrients by $50 \%$ and more. Dried grains of pollen have a hard shell (intine and exine) that can significantly affect the penetration of the digestive enzymes into the pollen pellets. The hard shell can affect the biodegradability, bioavailability and absorption of the important nutrients. In order to increase the digestibility and the functionality, the pollen grains should be ground and dissolved in warm water, whereby the accessibility of nutrients increases to 60 $80 \%[16]$.

Recently, due to the increased awareness of consumers the consumption of functional foods can improve their health and pollen began to be considered as a functional food and feed ingredient [16].

Moreover, a number of fermented pollen-based food products have been developed. Based on the study of adding bee collected pollen as food additives and supplementation can improve the food products and thus, significantly increased the content of sugars, proteins, ash, fibers, and polyphenols, and the antioxidant potential of the final products [60].

The thermal properties of pollen are very important, especially when pollen is used as a supplement in the products that require thermal treatment or roasting at higher temperatures may decompose the nutritional and functional constituents of pollen [60]. In recent years, bee pollen is considered to be one of the most bioactive products for human consumption. However, related to the construction of the chemical structure of pollen, it reduced the availability of adequate nutrients and bioactive compounds. Hence, before consumption, of bee pollen should be subject to the process of transformation [26].

According to Carlos et al., bee pollen has had a growth in consumption in recent years due to the recognition of its nutritional and bioactive potential. However, several reports have shown that the external structure of the grain limits the absorption of nutrients in the human gastrointestinal tract [61-63]. However, pollen grains structural modification could be achieved through fermentative processes, and favoring the release of compounds found in the pollen. Moreover, literature mentions that this natural modification improves the nutritional and bioactive characteristics of bee pollen [34]. The potassium, protein, dietary fiber and lipids levels in bee collected pollen indicated the possibility of using pollen as a dietary supplement. Moreover, further analysis focused on bioactive components and properties and characterizing the volatile fraction and sensory characteristics are recommended for fully characterizing Ethiopian bee pollens.

\section{Conclusion and Recommendations}

\section{Conclusion}

The quality of pollen is influenced by the harvesting techniques, technologies used, and post-harvest handling, drying and storage situations. Even though, some countries have national standard, there is no international standards that defining the compositional requirements of bee collected pollen. The chemical structure of pollen can reduced the bioavailability of adequate nutrients and bioactive compounds, in order to increase the digestibility and bioavailability pollen grains and therefore, further softening process and treatment is essentially important to crushed and dissolve the pollen grains. Compared to other food products, pollen and bee bread have a significant amount of biologically active nutrients that meet the human body needs to a good functioning of the immune system and resistance against illnesses, as well as supporting the healing processes.

Due to the small quantities that are consumed and required, pollen should be rather regarded as a supplement functional food. Application of bee collected pollen in the formulation of functional food products is in progress, and pollen's addition to a food matrix generally improves the nutritional, functional, techno-functional, and sensory properties of the newly formulated food products. Having diversified natural vegetation cover that used as a pollen source and having a large bee colony population in Ethiopia, pollen production is not a widely commercialized product. Therefore, promoting and supporting pollen production, postharvest handling and quality standard development, and commercialization aspects shall be the priority area of intervention.

\section{Recommendations}

- Bee collected pollen and bee bread are becoming a valuable and pronounced foods, however, further detailed studies on assimilation and bioavailability of the ingredients, health claims and applications shall be considerable areas of research. 
- Assessing the nutritional composition and bio-functional properties of pollens produced at different agro ecological area of Ethiopia shall be fundamentally important area of consideration.

- Commercializing production and promoting the biofunctional properties and health benefits of pollen can be a considerable area of apiculture industry development intervention in Ethiopia.

\section{References}

1. Srivastava P (2019) Status Report on Indian bee keeping and honey processing. $J$ Multi sweet Group 2-6.Birks H, Birks H, Ammann B (2016) The fourth dimension of vegetation. J Science 354: 412-413. [crossref]

2. Teng F, Soohyun P, Qian S, Xingyu Z, Qimin L, et al. (2020) Transformation of hard pollen into soft matter. J Nature Communications 11: 1-10.

3. Rodica M, Mirela S, Alina V, Erkan T, Banu Y, et al. (2019) Bee Collected Pollen and Bee Bread: Bioactive Constituents and Health Benefits. J Antioxidents 8: 568-578. [crossref]

4. Avni D, Hendriksma HP, Dag A, Uni Z, Shafir S (2014) Nutritional aspects of honey bee-collected pollen and constraints on colony development in the eastern Mediterranean. J Insect physiology 69: 65-73. [crossref]

5. Bogdanov S (2015) Pollen: Production, Nutrition and Health: A Review. J American College of Nutrition 1-30.

6. Sattler J, Melo D, Granato E, Araújo A, Freitas O, et al. (2015) Impact of origin on bioactive compounds and nutritional composition of bee pollen from Southern Brazil: A screening study. J Food Research International 77: 82-91.

7. Melo A, Estevinho J, Sattler B, Souza A, Freitas O (2016) Effect of processing conditions on characteristics of dehydrated bee collected pollen and correlation between quality parameters. J Food Science and Technology 65: 808-815.

8. Ares A, Valverde J, Bernal M, Nozal J, Bernal (2018) Extraction and determination of bioactive compounds from bee pollen. J Pharmaceutical and Biomedical Analysis 147: 110-124. [crossref]

9. Anderson K, Carroll M, Sheehan T, Mott B, Maes P, et al. (2014) Hive-stored pollen of honey bees: many lines of evidence are consistent with pollen preservation, not nutrient conversion. Mol Ecol 23: 5904-5917. [crossref]

10. Pierre L, Vaughn B, James D, Zachary Y, Huang J, et al. (2019) Seasonal variation of pollen collected by honey bees (Apis mellifera) in developed areas across four regions in the United States. J Plose One 14: 1-24. [crossref]

11. Dhananjay V, Snehal K, Dhananjay M (2019) Solid State Fermentation of BeeCollected Pollen. J Current Microbiology and Applied Sciences 8: 1557-1563.

12. Barene I, Daberte I, Siksna S (2015) Investigation of bee bread and development of its dosage forms. J Medicine 21: 16-22.

13. Tomás A, Falcão S, Russo P, Vilas M (2017) Potentialities of beebread as a food supplement and source of nutraceuticals: Botanical origin, nutritional composition and antioxidant activity. J Apic Res 56: 219-230.

14. Habryka C, Kruczek M, Drygas B (2016) Bee products used in apitherapy. World Scientific News 48: 254-258.

15. Kieliszek M, Piwowarek K, Kot A, Chlebowska A (2018) Pollen and bee bread as new health-oriented products ;A review. J Trends in Food Science and Technology 71: 170-180.

16. Deveza M, Keller K, Lorenzon M, Nunes L, Sales É, et al. (2015) Mycotoxicological and palynological profiles of commercial brands of dried bee pollen. Brazilian. $J$ Microbiology 46: 1171-1176. [crossref]

17. Kaškoniene V, Kaškonas P, Maruška A (2015) Volatile compounds composition and antioxidant activity of bee pollen collected in Lithuania. J Chemical Papers 69: 291299.

18. Fuenmayor B, Zuluaga D, Díaz M, María C, Saverio M (2014) Evaluation of the physicochemical and functional properties of Colombian bee pollen. J MVZ Córdoba 19: 4003-4014
19. Denisow M (2016) Influence of the commercial processing and floral origin on bioactive and nutritional properties of honey bee-collected pollen. J Sci Food Agric 96: 4303-4309.

20. Canale A, Benelli G, Castagna A, Sgherri C, Poli P, et al. (2016) Microwave-assisted drying for the conservation of honeybee pollen. J Materials 9: 363.

21. Ranieri A, Benelli G, Castagna A, Sgherri C, Signorini F, et al. (2019) Freeze-drying duration influences the amino acid and rutin content in honeybee-collected chestnut pollen. Saudi J Biol Sci 26: 252-255. [crossref]

22. Carlos B, Carlos D, Consuelo M, Marta C, María C, et al. (2014) Evaluation of the physicochemical and functional properties of Colombian bee pollen. J Revista MVZ Córdoba 19: 4003-4014.

23. Vaida A, Vilma K, Paulius K, Karolina B, Audrius M (2019) Comparison of Physicochemical Properties of Bee Pollen with Other Bee Products. J Biomolecules 9: 819. [crossref]

24. Parvanov P, Dinko D (2017) Proposals for desiccated bee pollen production and labeling. J Nutr Hum Health 1: 13-16.

25. Zuluaga C, Serrato J, Quicazan M (2015) Chemical, nutritional and bioactive characterization of colombian beebread. J Chemical Engineering Transactions 43: 175-180.

26. Fernandes P, Serrão J (2000) Nutritive value and apparent digestibility of beecollected and bee-stored pollen in the stingless bee. J Apidologie 31: 39-45.

27. Adriana U, Liviu Al, Daniel S, Carmen I (2017) Chemical Composition and Biological Activities of Beebread Review. J Bulletin of University of Agricultural Sciences and Veterinary Medicine 74: 1-9.

28. Markiewicz R, Naliwajko SK, Bartosiuk E, Moskwa J, Isidorov V, et al. (2013) Chemical composition and antioxidant activity of beebread, and its influence on the glioblastoma cell line (U87MG). J Apiculture Science 57: 147-157.

29. Campos M, Olena L, Anjos O (2016) Chemical composition of bee pollen. Chemistry, biology and potential applications of honeybee plant-derived products. Bentham eBooks 67-88.

30. Anjos O, Santos A, Dias T, Estevinho L (2017) Application of FTIR-ATR spectroscopy on the bee pollen characterization. J of Apicultural Research 56: 210-218.

31. Leila F, Daiane P, Bianca R, Ligia B, Almeida M, Solange T (2019) Fortification of beef burger with the addition of bee pollen from Apis mellifera. J Food and Agriculture 31: 895-901.

32. GENÇAY Ç, Nezahat P (2017) Protein Analysis of Anzer Bee Pollen by Bradford Method. J Food Chemistry 17: 21-32.

33. Bogdanov S (2011) The Bee Pollen Book. Muehle thurnen, Switzerland: J Bee Product Science 1-14.

34. Estevinho M, Afonso S (2011) Antifungal effect of lavender honey against Candida albicans, Candida krusei and Cryptococcus neoformans. J Food Science and Technology 48: 640-643. [crossref]

35. Antonella C, Giovanni B, Giuseppe C, Cristina S, Francesca S, et al. (2020) Drying Techniques and Storage: Do They Affect the Nutritional Value of Bee-Collected Pollen. J Molecules 25: 1-15. [crossref]

36. Maria G, Campos Bogdanov S, Chirstian Frigerio (2010). What is the future of BeePollen. J Api-Product and Api-Medical Science 2: 131-144.

37. Marek K, Kamil P, Anna M, Kot S, Anna C (2018) Pollen and bee bread as new healthoriented products: A review. J Trends in Food Science \& Technology 71: 170-180.

38. Melo A, Estevinho M, Almeida L (2015) A diagnosis of the microbiological quality of dehydrated beepollen produced in Brazil. J Applied Microbiology 61: 477-483. [crossref]

39. Bobis O, Marghitas I, Dezmirean D, Morar O, Bonta V, et al. (2010) Quality Parameters and Nutritional Value of Different Commercial Bee Products. $J$ Sci Biotechnol 67: 1-2.

40. Margaoan R, Strant M, Varadi A, Topal E, Yücel B, et al. (2019) Bee Collected Pollen and Bee Bread: Bioactive Constituents and Health Benefits. J Antioxidants 8: 568.

41. Komosinska K, Olczyk P, Kaźmierczak J, Mencner L, Olczyk K (2015) Bee pollen Chemical composition and therapeutic application. Evidence based Complementary and Alternative Medicine J Hindawi 2015: 297425. [crossref] 
42. Koroglu A (2018) Bee pollen and its pharmacological properties. J Bio-molecules 27: 93-97.

43. Ivanisova E, Kacaniova M, Francakova H, Petrova J, Hutkova J, et al. (2015) Bee bread perspective source of bioactive compounds for future Scientific Journal for Food Industry 9: 592-598.

44. Afra M (2018) Bee pollen properties: uses and potential pharmacological applications-a review. J Analytical and Pharmaceutical Research 7: 513-515.

45. Nemat K, Yadollah S, Mahdi M (2009) Chronic inflammation and oxidative stress as a major cause of age-related diseases and cancer. J National Library of Medicine 3: 73-80. [crossref]

46. Anna R, Agata K, Robert K., Krzysztof J, Maciej K, et al. (2018) Protective Effect of Polyphenol-Rich Extract from Bee Pollen in a High-Fat Diet. J Library of medicine 23: 805. [crossref]

47. Nanias P, Sandra R, Alfredo T, Xesus F, Leticia M (2014) Biological activities of commercial bee pollens: antimicrobial, antimutagenic, antioxidant and antiinflammatory. J Food Chemistry Toxicol 63: 3-9. [crossref]

48. Aleksandar Ž, Danijel D, Miroljub B, Mohammad A, Mirjana B (2020) The Application of Pollen as a Functional Food and Feed Ingredient;-The Present and Perspectives. J Biomolecules 10: 2-36. [crossref]

49. Mirjana M, Jelena T, Irena V, Branko Š, Dušanka M (2019) Phenolic Composition Influences the Health-Promoting Potential of Bee-Pollen. J Bio-molecules 9: 783. [crossref]

50. Avsar C (2016) Phenolic Composition, Antimicrobial and Antioxidant Activity of Castanea sativa Mill. Pollen Grains from Black Sea Region of Turkey. J International Food Research 23: 1711-1716.

51. Arruda V, Pereira A Estevinho L, Almeida L (2013) Presence and stability of B complex vitamins in bee pollen using different storage conditions. J Food Chem Toxicol 51: 143-148. [crossref]
52. Di Cagno R, Filannino P, Cantatore V, Gobbetti M (2019) Novel solid-state fermentation of bee-collected pollen emulating the natural fermentation process of bee bread. J Food Microbiol 82: 218-230.

53. Urcan A Marghitas L, Dezmirean D, Bobis O, Bonta V, Mure C, et al. (2017) Chemical Composition and Biological Activities of Beebread Review. J Sci Biotechnol 7: 4-6.

54. Velásquez P, Rodríguez K, Retamal M, Giordano A, Valenzuela L, et al. (2017) Relation between composition, antioxidant and antibacterial activities and botanical origin of multifloral bee pollen. J Appl Bot Food Qual 90: 306-314.

55. Araújo S, Chambó E, Costa M, Cavalcante S, Silva D, et al. (2017) Chemical Composition and Biological Activities of Mono and Hetero floral Bee Pollen of Different Geographical Origins. J National Library Medicine 18: 921. [crossref]

56. Silva T, Natividade C, Silva F (2014) Identification of sugar, amino acids and minerals from the Pollen of jandarra stingless bees (Melipona subnitida). J Food and Nutrition Science 5: 1015-1021.

57. Dominguez D, Bohoyo GD, Herna MT, Gonzalez D (2011) Influence of the commercial processing and floral origin on bioactive and nutritional properties of honey bee-collected pollen. J Food Science and Technology 46: 2204-2211.

58. Admassu k, Ensermu S, Teshome G, Peter B, Lulsegde M (2017) Proximate composition and antioxidant power of bee collected pollen from moist Afromontan forests in southwest Ethiopia. J Agricultural Science Research 7: 83-95.

59. Krystyjan M, Gumul D, Ziobro R, Korus A (2015) The fortification of biscuits with bee pollen and its effect on physicochemical and antioxidant properties in biscuits. J Food Sci Technol 63: 640-646.

60. Carlos M, Zuluaga D, Marta Q (2019) Effect of fermentation on structural characteristics and bioactive compounds of bee-pollen based food. J Apic Sci 63: 1-14.

61. Bogdanov S (2016) Pollen Collection, Harvest, Composition, Quality The Bee Pollen Book 1-14.

62. Mărgăoan L, Mărghitas D, Dezmirean C, Mihai O (2010) Bee Collected Pollen General Aspects and Chemical Composition, Bulletin USAMV. Animal Science and Biotechnologies 67: 254-259.

\section{Citation:}

Eshete Y (2021) Bee Pollen Production, Physicochemical and Bio-functional Properties, and Safety Utilization: A Review. Nutr Res Food Sci J Volume 4(1): 1-10. 